Sven Tarp*

\title{
The Third Leg of Two-legged Lexicography
}

\begin{abstract}
This article argues that the essence of lexicography is its capacity to satisfy the potential users' punctual information needs in contrast to their global information needs. Simultaneously it shows that lexicographic theory, which so far has studied only two basic types of social situations where information needs may occur, the communicative and cognitive ones, should also study a third type of basic situations, which are referred to as operational user situations. On this basis, the article projects lexicography beyond the limits of known dictionaries considered as products of applied linguistics and discusses the relation that should be established between lexicography and other branches of human knowledge. It argues that lexicography, focusing on its core specialities, has a lot to contribute to these branches of knowledge. In this respect, it discusses not only traditional dictionaries but also the benefit that authors of handbooks, manuals, how-to's, user guides, textbooks and other types of texts may have from a renewed lexicographic theory that focuses on quick and easy access to data from which the potential users and readers may retrieve the information needed in specific situations. Finally, it argues that a number of university study programs may benefit from short courses on the core specialities of lexicography.
\end{abstract}

\section{Introduction}

We do not know what thoughts went through the minds of those Indian and Chinese priests who several thousand years ago produced the first dictionaries. But we know that even if their individual steps may seem small, in reality they represented a gigantic step for humanity, probably more important than the famous step taken by Neil Armstrong in 1969, although far more anonymously.

From the very beginning, dictionaries have been closely related to written language in two ways. Firstly, dictionaries came into the world as solutions to problems inherent in written language. With written lan-

* Sven Tarp, Associate Professor, Dr.ling.merc.

Aarhus School of Business, University of Aarhus

Centre for Lexicography

Fuglesangs Allé 4

DK-8210 Aarhus V

st@asb.dk

Hermes - Journal of Language and Communication Studies no 40-2008 
guage the religious beliefs and doctrines which played an important role in those ancient cultures and which in the past had been transmitted orally from generation to generation, and modified correspondingly, were now written down and transformed into holy scriptures that were, so to say, frozen in the language of a given generation at a specific time in history. With the passing of time, these texts became increasingly more difficult to understand and ended up being texts written in a language that was, in fact, considered an entirely foreign language by the new generations. To solve this serious problem, dictionaries were invented as tools that permitted continuous reading and understanding of the old scriptures.

Secondly, dictionaries have, by their very nature, contained written language for 4000 years. It is only the last few decades, with the development of computer technology, that have seen the possibility of producing oral dictionaries as well, a possibility that has so far not been sufficiently explored. In this respect, the coming decades may not only see a continuous transition from printed to electronic dictionaries, but probably also from written to oral ones.

However, the development of future generations of dictionaries is not only a practical problem in terms of adequate software and skilled lexicographers, but also a theoretical question, which includes a solution to the identity crisis lexicography is now experiencing. This crisis has developed and deepened step by step over several decades and is closely related to the progress made in the theoretical field. The identity crisis expresses itself in a kind of schism between the majority of the dictionaries produced today and the most advanced lexicographic theories which have, so far, only influenced lexicographic practice on a very limited scale. When all the details and secondary aspects are omitted, what remains in the centre of this identity crisis is the fundamental question: What is the essence of lexicography? Is it the traditional dictionaries considered as products of applied linguistics and only slightly modified according to the new technologies and needs? Or is it something completely different?

\section{The essence of lexicography}

Lexicographic thinking and theory building during the last hundred years or more have increasingly focused on users and their needs. User- 
orientation and user-friendliness have been at the centre of most of the competing theoretical paradigms developed during this period. As a result, dictionaries have increasingly been regarded as utility products produced with the genuine purpose of meeting the various needs of potential user groups. However, a major problem has been to determine the nature of these needs and, consequently, the real content of the concept of user-friendliness. It goes without saying that the concrete user needs will be extremely diverse and varying, but on the other hand it is also evident that not all human needs can be satisfied by means of dictionaries. The goal is therefore to define the fundamental and common nature of the lexicographically relevant user needs. In this regard, when an abstraction is made from the huge variety of concrete user needs, what remains is that user needs in terms of lexicography are always needs for information.

Dictionaries are not the only written sources that provide assistance to people with information needs. Newspapers, journals, magazines, books, textbooks and internet-based texts are other such sources. However, dictionaries distinguish themselves in various aspects in comparison with the other text sources. Firstly, almost without exception, dictionaries are not designed to be read from one end to the other, but to be consulted. This means, as a rule, that the needs which they are designed to satisfy are not global information needs, but punctual information needs whether or not these needs are related to global issues. (This distinction between global and punctual issues was first introduced by Hausmann (1977), who also accepted dictionaries for global issues.)

Secondly, the user's information needs in terms of lexicography are never abstract needs, i.e. they are not "just needs". On the contrary, they are always - or should always be - viewed as concrete needs that are closely related, not just to a concrete user, but to a concrete user finding himself in a concrete situation, e.g. text reception with all its possible problems in terms of understanding and the corresponding needs to get assistance to solve these problems. Consequently, the user needs in terms of lexicography are always treated as specific types of needs related to specific types of users finding themselves in specific types of extra-lexicographic social situations.

As a rule, none of the other information sources listed above are primarily designed to provide assistance to people with punctual and 
situation-dependant information needs. Although they are frequently planned to assist a specific type of users, they seldom take into account the various types of social situations where user needs may arise. Besides, they are in most cases conceived to be read from one end to the other and this, of course, is reflected in their general structure and accessibility. By analogy, the nature of dictionaries as tools for specific purposes and punctual consultation is also reflected in their overall design and accessibility. In fact, one of the basic characteristics of dictionaries is that they provide - or are expected to provide - quick and easy access to the data from which the needed information may be retrieved (Nielsen 2007, Tarp 2007).

To sum up, the essence of lexicography is its capacity to conceive and produce utility tools that can be consulted by specific types of users in order to acquire the type of information they may need in specific types of situations. As such, lexicography has a lot to contribute to a society where information is increasingly needed in people's personal and professional life and which even defines itself as an information and knowledge society. In order to play this role it is necessary that lexicography projects itself beyond the limits of known dictionaries considered as products of applied linguistics and throws itself into the future with all its renewed theoretical and practical energy.

\section{Information and knowledge}

The terms information and knowledge are increasingly being used and abused in modern society (cf. Wiegand 2000). Many people use these terms without knowing their real meaning and when they are eventually defined, the definitions vary a lot. For instance, looking up under information in Wikipedia, one finds the following explanation and comment:

"Information is the result of processing, manipulating and organizing data in a way that adds to the knowledge of the receiver. In other words, it is the context in which data is taken. Information as a concept bears a diversity of meanings, from everyday usage to technical settings. [...] the word "information" is often used without careful consideration of the various meanings it has acquired”. (Wikipedia, 12 July, 2007) 
It is only natural that definitions of central categories may vary from science to science, and even from theory to theory within the same science, as they all have their particular approach to these categories. Lexicography also needs its own definition of the category of information. The methodology established by the function theory as to the terms shared with other branches of human knowledge is that the definitions used by these branches should never be taken over uncritically, but should always be submitted to an analysis in order to determine whether they should be taken over unchanged, modified according to lexicographic theory or totally rejected. In this respect, the lexicographic function theory agrees with the above short definition from Wikipedia that a distinction should be made between data and information and that the latter "is the result of processing [...] data", but it does not agree that the information is necessarily something that is processed, manipulated and organised "in a way that adds to the knowledge of the receiver".

Many researchers - and not only some lexicographers - speak about knowledge and information as being included in dictionaries and other text types. However, knowledge and information cannot be taken out of dictionaries and other texts as if they were canned tuna fish where the tuna fish can be taken out just by opening the can. Information and knowledge can only be retrieved from texts through a cognitive process - involving mental activities that lexicography does not study - and where the result and success of the process depend on the particular user's cognitive and mental abilities. For instance, a person with no Japanese language skills will hardly be able to extract any useful information from a Japanese text, even when the "information" that he or she needs is "included" in the text. Consequently, it is necessary to distinguish between what is included in texts and what is retrieved from them. In this respect, the lexicographic function theory, which is inspired by a more or less similar distinction made by Wiegand (1998, 2000, 2002), distinguishes between the lexicographic data contained in the dictionary and the information that the user may or may not be able to extract from these data. As a result, user-friendliness is not only a question of selecting the relevant data but also of presenting them in such a way that the user can actually retrieve the needed information. It stands to reason that a specific user typology and user profile providing information about the real - and not an abstract - group of users is a sine qua non in this search for user-friendliness. 
As already stated, while the function theory agrees with the above definition from Wikipedia in terms of a conceptual distinction between data and information, it does not agree that the information is necessarily something that is retrieved "in a way that adds to the knowledge of the receiver". As to lexicography, users may need information for a huge variety of purposes. Sometimes they may need information in order to add it to their existing knowledge. But on other occasions they may need it in order to solve specific problems, e.g. related to a communication process, and whether or not it is added to the memory as new knowledge is a completely secondary question for them. In this view, the information retrieved from the lexicographic data is considered a sort of "proto-knowledge" with the potential of being transformed into real knowledge, i.e. stored in the memory, but also to be used for other purposes and then, perhaps, forgotten.

The relativization of the possibility and necessity of information to be transformed into knowledge is very important to lexicography, which deals with several anticipated user situations, e.g. the communicative ones, where the direct and immediate purpose of a dictionary consultation is not to add to the users' existing knowledge, as well as other situations where this is actually the real purpose of the consultation. Of course, it can be claimed that, in many cases, the information retrieved during the first type of consultations may eventually be stored as knowledge. In this regard, however, it is important to take into consideration that this is not the immediate and direct purpose of the dictionary consultation, but a sort of fortunate by-product.

\section{User typology}

A central issue in lexicography is the establishment of dictionary user typologies. In doing so, lexicography only focuses on the user characteristics that are relevant to the design of dictionaries, i.e. the characteristics that require differentiated lexicographic solutions. A basic typology can be prepared on the basis of the following nine questions:

1. What is the mother tongue of the users?

2. To what extent do they master their mother tongue?

3. To what extent do they master a specific foreign language?

4. To what extent do they master a specific specialised language in their mother tongue? 
5. To what extent do they master a specific specialised language in a foreign language?

6. How much experience of translation do they have?

7. How great is their general cultural knowledge?

8. How great is their knowledge of culture in a specific foreign-language area?

9. How great is their knowledge of a specific subject or science?

It is important to note that this list is both an open and a facultative list. On the one hand, not all the questions listed have relevance to a specific dictionary project. On the other hand, for some specific dictionary projects other questions may be raised in order to prepare a useful typology. For instance, Tarp (2008) suggests three additional questions in terms of learner's dictionaries. Consequently, if new social situations are discovered where dictionaries or other lexicographic tools may assist potential users with information needs, lexicography is prepared to add new questions to the ones listed above in order to prepare user profiles and user typologies, on the basis of which new types of dictionaries and lexicographic tools can be designed and produced.

\section{Cognitive user situations}

So far, the lexicographic theory has discussed two fundamental types of user situations, the cognitive ones and the communicative ones. Of these two situations, the latter - which embraces text production, reception, translation, marking, revision and proofreading - is the one that has been most thoroughly treated and analysed in the theoretical literature. However, it is of vital importance for lexicographic theory to advance towards a similar understanding of the cognitive user situations which have up till now been defined in contrast to the communicative user situations as the ones where users for one reason or another want or need to acquire knowledge about a specific phenomenon. This need to acquire new knowledge can arise in countless social situations, for instance:

1. while reading: the sudden need to get additional encyclopaedic knowledge in order to understand the text;

2. while writing: the need to know more about a given topic in order to finish a text; 
3. during discussions with other people: the need to clarify a specific issue;

4. during processes in the subconscious: the sudden desire to examine something;

5. during dictionary consultation: the desire to know more about a specific topic;

6. during preparation for specialised translation and interpretation tasks: the need to learn more about the subject field in question;

7. in relation to a teaching programme: the need to know more about a specific subject field;

8. in relation to a course of study: the need to know more about a specific subject field;

9. $(\ldots)$

The options are infinite. However, even on the basis of this limited selection it is possible to deduce at least the following three preliminary conclusions:

First conclusion: Of the above eight situations, the first five are isolated situations without any clear relation to previous or subsequent situations giving rise to dictionary consultation, while the last three ones are situations where the potential dictionary user is making - or supposed to make - a systematic effort to gradually acquire knowledge about a specific subject field and where a specific consultation in one or the other way is related to previous or subsequent consultations. The two general types of situations may be called sporadic and systematic user situations, respectively (cf. Tarp 2008). In both types of situations, users may have information needs regarding punctual issues, but what characterises the systematic user situation in comparison with the sporadic one is that here the punctual issues are always related to global issues. This distinction between systematic and sporadic situations has big consequences for the design of a dictionary or of another type of lexicographic tool, because the needs arising from a systematic study of a given subject field will require a more sophisticated lexicographic datadistribution structure as well as a highly developed system of cross-references or links that allow users to navigate in order to get full use of the data made available through the lexicographic tool. 
Second conclusion: In the systematic situations, it is evident that the purpose of the dictionary consultation is to add to the users' existing knowledge (cf. the quoted explanation from Wikipedia). However, at least in two of the other situations (2 and 3), the direct purpose of the consultation is to meet an immediate knowledge need and whether or not the information is added to the user's existing knowledge, i.e. stored in the memory, is supposed to be a secondary question for the user. When a journalist, for instance, is writing an article about Newton and has to tell the readers the date of birth of this great scientist, he or she may then consult a dictionary with the immediate purpose of getting this specific information, which he or she may never need again and probably forget within a few minutes. In such cases, the information is used and consumed in its temporary form of proto-knowledge and not in its eventual form of stored knowledge.

Third conclusion: In situations (1), (2) and (6), the needs for knowledge are directly related to an ongoing or future communication process and, as such, they could be included among the needs arising during this process. However, from a lexicographic point of view, i.e. in terms of the possible consequences for dictionary concepts, it is necessary to distinguish between the users' inadequate linguistic and other communicative skills on the one hand and the possible lacunae in their general or specialised encyclopaedic knowledge on the other hand. For instance, if a person is reading a specific text, it is frequently necessary to possess additional encyclopaedic knowledge in order to understand the general context in which the text is written and thus the text itself. As to text production, an analogous distinction should be made between what is to be communicated and how it should be communicated where the latter concerns the text producer's linguistic and communicative skills while the former concerns his or her general or specialised encyclopaedic knowledge. The same holds true for translation where translators frequently need knowledge about either the general context or the subject field of the text to be translated. This knowledge is of a different nature than the translators' general translation skills, including their proficiency level in terms of specialised vocabulary. The persons engaged in the three mentioned types of communication (1) may have the necessary knowledge in advance, (2) they may acquire it through a systematic study before starting the communication process, and (3) they may acquire it when their lack of knowledge becomes a problem 
during this process. It is evident that both situations (2) and (3) are part of the communication process in the broad sense of the word. However, if situation (2), i.e. a systematic study of a given subject field, occurred without relation to a communicative situation, it would clearly be considered a cognitive situation. On the other hand, the only real difference between situations (2) and (3) is temporal, i.e. between the different moments when the needs occur and give rise to a lexicographic consultation. In this regard, the two types of situations are, in fact, cognitive situations related to communicative situations.

Although it could be argued that there is some integration of the cognitive and communicative situations (cf. Tarp 2005), it is, nevertheless, important to distinguish between them inasmuch as the user needs arising in these two basic types of user situations require different lexicographic solutions and in many cases also dictionary authors with completely different skills.

\section{Operational user situations}

The theoretical literature contains some sporadic references to reference works like handbooks, manuals, and how-to's. These references have not been properly discussed in any known contribution, but it is easy to see that many of these reference works, especially the how-to's, are not designed to provide assistance in either cognitive or communicative situations, but to give directions and instructions on how to proceed in specific situations, e.g. when operating machines or preparing an annual statement according to the national requirements. Such situations may be called operational user situations and have so far not been integrated into any known lexicographic theory.

It is a matter of course that that not all handbooks, manuals or howto's are designed as lexicographic products, but there is no reason why they should not be conceived and considered as such. When an abstraction is made from their specific forms, contents and purposes, they have all something fundamental in common with traditional lexicographic products, i.e. that they are utility tools exclusively or partially designed to be consulted by specific types of users in order to satisfy specific types of information needs in specific types of social situations and, as such, they are expected to provide easy and quick access to the data from which the needed information can be retrieved. In this regard, 
a lexicographic theory that focuses on easy and quick access to data from which user and situation-adapted information can be extracted has clearly a lot to contribute to the design of a new generation of improved handbooks, manuals, and how-to's. Moreover, to this list of lexicographically relevant reference works should be added other tools such as user guides which are frequently not only used to be read from one end to the other, but also - and even mainly - for punctual consultation in order to get information that can be transformed into directions or instructions on how to proceed in operational situations very similar to those where handbooks, manuals and how-to's may provide assistance. All these reference works that are traditionally used to solve problems and doubts in relation to operational situations could benefit from a lexicographic approach that analyses the types of information needs that may arise for specific types of users in the various types of operational situations in order to prepare new types of lexicographic tools with quick and easy access to the relevant data.

In this respect, a tenth question should be added to the nine questions listed above in order to prepare a typology of users with needs related to operational situations. Just as it is important to distinguish between the potential users' language knowledge and language skills in terms of learner's lexicography (cf. Tarp 2008), in operational situations it is also important to distinguish between the potential users' knowledge and skills in terms of the subject or task in question. An engineer, for instance, may have great theoretical knowledge about a certain machine but he or she may not be able to operate it as well as a skilled worker who may not possess theoretical knowledge of the machine, but "only" operational skills obtained through training and long experience. Consequently, the tenth question relevant to a user typology for operational situations could be formulated as follows:

\section{To what extent do they have operational skills related to a specific sub- ject?}

Of course, this question cannot stand alone but should be combined with some of the other questions listed above. In this respect, it is also of special importance to know the language skills of the anticipated user group in terms of written language. 


\section{The partially ignored user situations}

As indicated above, dictionaries are not the only source from which information can be retrieved. Newspapers, journals, magazines, books, textbooks and internet-based texts were mentioned as other such sources. As have been seen, handbooks, manuals and even user guides can be added to this list. It was also stated that dictionaries distinguish themselves from the other sources in the sense that they are mainly designed to be consulted punctually and not to be worked through from one end to the other although the discussion in the previous section showed that in some cases they are also partially conceived to be studied in this way.

The interesting point is now that some of the other sources are also used for punctual consultation purposes, at least partially. This is especially the case with handbooks, manuals, how-to's and user guides. But also textbooks are used both to be studied globally from one end to the other and to be consulted punctually in case of doubt or memory problems, e.g. during the preparation for examinations. The usual method to provide for this specific cognitive user situation is on the one hand to prepare detailed tables of content and, on the other hand, to compile indexes containing the most important words, terms and names used in the text. Both components are examples of prepared and anticipated access routes (cf. Bergenholtz/Gouws 2007).

It goes without saying that detailed and well-structured tables of content always benefit users although they need to be complemented with indexes in order to provide for all the users' needs in terms of access routes. However, indexes, especially if they are created automatically, frequently suffer from the same kind of problems as produced by searches on the internet, i.e. they furnish a lot of redundant references appearing in a chaotic order without any priority. As a result, the search for data from which the needed information can be retrieved is far from a quick and easy process, for which reason the user-friendliness in terms of consultation is considerably reduced in these text types. The way to solve this time-consuming problem is not only to produce indexes with prioritized references. Such indexes are clearly an advantage for the reader but the real solution is to plan a well-considered data-distribution structure that ensures that all the main categories and concepts relevant to the subject are treated and explained globally in specific and lo- 
gic places (positions), either within the through-going text or in special inserted text parts, frequently called middle matter. And this data-distribution structure should furthermore be supported by a well-considered layout where the relevant keywords appearing in the mentioned positions are highlighted by means of bold letters or special symbols so as to facilitate the quick and easy access to these positions.

\section{Conclusions}

So far, the lexicographic function theory has been supported by two legs, i.e. the communicative and cognitive user situations, but the above discussion has discovered a third fundamental type of user situations, the operational ones, that should be added as the third leg of lexicography. Whether lexicography from this point should be regarded as threelegged or as two-legged with two of the legs subordinated to the same type of general situation is something that has to be discussed and resolved in the future. But various factors indicate that the communicative and operational situations have something in common which distinguish them from the cognitive ones, i.e. they both require immediate action whether linguistic or practical.

However, even more important than the typological consequences of the above discussion are the practical and educational ones. It has been argued that lexicography has a lot to contribute to other disciplines and sciences, but it is important to be realistic about the scope and limitations of this contribution. Lexicography has no intention to lexicographize other disciplines and sciences and swallow them up like an octopus. Quite the contrary, lexicography does not want to influence the core specialities and activities of these disciplines and sciences, but only the part of them where the results of their research and theoretical discussion are presented in the form of texts that are, at least partially, planned to be consulted. Furthermore, the core speciality of lexicography is precisely this, i.e. to provide access routes that can guarantee a quick and easy consultation process when information about punctual issues is needed.

In reality, there is nothing new in this. Historically, lexicography has been known for its interdisciplinarity. It has been collaborating closely with researchers and skilled personnel from a lot of different disciplines and sciences, although one of these, linguistics, with which it has had 
particularly close collaboration, has tried to proclaim ownership and reduce lexicography to a sort of applied version of itself. The real core specialities of lexicography, independent of its collaboration with any other branches of knowledge, include:

1. Preparation of user profiles including all relevant user characteristics

2. Description of relevant extra-lexicographic user situations

3. Definition of information needs related to specific types of users and user situations

4. Selection and preparation of data from which the needed information can be retrieved

5. Preparation of quick and easy routes to the relevant data

6. Systematisation of a specific subject field

7. General principles of layout and design related to lexicographic tools

The conclusion that can be drawn from the above discussion is that, on the one hand, lexicography must concentrate on and further develop these core specialities and, on the other hand, cultivate and further strengthen its collaboration with other disciplines and sciences. This does not only mean that lexicography should continue to focus on its own research activities and at the same time collaborate with specialists from other branches when they need dictionaries and other types of lexicographic tools. Lexicography should also prepare highly specialised short courses for university students and other people who later in their careers are supposed to produce textbooks, manuals, handbooks, howto's, user guides, indexes and even web portals, which are at least partially planned to be consulted. In this respect, the general teaching programs of the Department of Language and Business Communication at the Aarhus School of Business could definitely benefit from the inclusion of a short course on the core specialities of lexicography.

The gauntlet is down!

\section{Literature}

Bergenholtz, Henning and Rufus H. Gouws 2007: The access process in dictionaries for fixed expressions. In Lexicographica. International Annual for Lexicography 23. (To appear)

Hausmann, Franz Josef 1977: Einführung in die Benutzung der neufranzösischen Wörterbücher. Tübingen: Niemeyer. 
Nielsen, Sandro 2007: Lexicographical Information Costs. In J.E. Mogensen and H. Gottlieb (eds.): Symposium on Lexicography XIII. Proceedings of the Thirtheenth International Symposium on Lexicography May 3-5, 2007, at the University of Copenhagen. Amsterdam: Benjamins. (To appear)

Tarp, Sven 2005: The pedagogical dimension of the well-conceived specialised dictionary. In Ibérica Journal of the European Association of Languages for Specific Purposes No 10, 7-21.

Tarp, Sven 2007: Lexicography in the information age. In Lexikos 17, 170-179.

Tarp, Sven 2008: Lexicography in the borderland between knowledge and non-knowledge. General lexicographical theory with particular focus on learner's lexicography. Tübingen: Niemeyer. (= Lexicographica Series Maior 134)

Wiegand, Herbert Ernst 1998: Wörterbuchforschung. Untersuchungen zur Wörterbuchbenutzung, zur Theorie, Geschichte, Kritik und Automatisierung der Lexikographie. 1. Teilband. Berlin/New York: de Gruyter.

Wiegand, Herbert Ernst 2000: Wissen, Wissenrepräsentationen und Printwörterbücher. In Ulrich, H., S. Evert, E. Lehmann and C. Rohrer (eds.). Proceedings of the Ninth Euralex International Congress, Euralex 2000. Stuttgart, Germany, August $8^{\text {th }}-12^{\text {th }}$, 2000. Volume 1. Universität Stuttgart: Institut für Maschinelle Sprachverarbeitung, 15-38.

Wiegand, Herbert Ernst 2002: Wissen in der Sprachlexikografie. Ein Plädoyer für einige immer noch notwendige Differenzierungen. In K. Ezawa, W. Kürschner, K.H. Rensch and M. Ringmacher (eds.). Linguistik jenseits des Strukturalismus. Akten des II. Ost-West-Kolloquiums Berlin 1998. Tübingen: Gunter Narr Verlag, 265-281.

Wikipedia. The free encyclopedia. http:// en.wikipedia.org (12 July 2007). 


\section{When talk is a science ....}
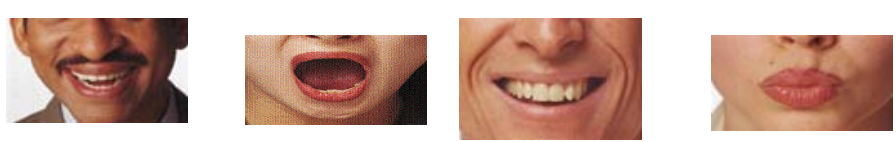

\section{CSA Linguistics \& Language \\ Behavior Abstracts}

Comprehensive, cost-effective, timely coverage of current ideas in linguistics and language research

Abstracts of articles, books, and conference papers from more than 1,100 journals plus citations of relevant dissertations as well as books and other media.

Available in print or electronically through CSA Illumina (www.csa.com).

14,000 Records /Year • Updated Monthly • Backfiles to 1973 380,000 Total Records $\bullet$ Thesaurus Available

Contactsales@csa.com for trial Internet access or a sample issue.

$$
\text { Pro Quest CSA }
$$

